\title{
O DELITO PENAL À LUZ DA TEORIA ECONÔMICA DO CRIME
}

\author{
Turíbio Marques Gonçalves Júnior ${ }^{1}$ \\ Bernardo Ricciardi dos Santos Brum ${ }^{2}$ \\ João Pedro Andrades Salles Soares ${ }^{3}$ \\ Pedro Antônio Lorentz Martins ${ }^{4}$ \\ Tiago Vargas Guedes ${ }^{5}$ \\ Fábio Rafael Corrêa Oliveira ${ }^{6}$
}

RESUMO: O presente desenvolvimento científico de pesquisa tem por objetivo principal explorar o estudo da Criminologia e o fenómeno criminal através da teoria do crime, com objetivos de buscar entender o que leva o criminoso a cometer crimes de viés econômico. O tema é importante devido ao aumento de crimes nos últimos anos, o estudo das causas do crime, a desorganização social, o que leva certas pessoas a cometerem crimes e por que é que na nossa sociedade existe um determinado índice de criminalidade. Esta atribuição intelectual, que delonga atender a procura de explicações que caracterizam o ser humano, fundamenta plenamente, desde já, a Criminologia.

Palavras- chave: Criminologia. Teoria do crime. Pena.

ABSTRACT: The main objective of this scientific research development is to explore the study of Criminology and the criminal phenomenon through the theory of crime, with the aim of trying to understand what makes the criminal commit crimes with an economic bias. The theme is important due to the increase in crimes in recent years, the study of the causes of crime, social disorganization, what makes certain people commit crimes and why in our society there is a certain crime rate. This intellectual attribution, which delays meeting the search for explanations that characterize the human being, fully bases, from now on, Criminology.

Keywords: Criminology. Crime theory. Pity.

\section{INTRODUÇÃO}

As atividades criminosas têm sido objeto de questionamento dos mais diversos meios - acadêmicos e também de outras esferas da sociedade - sobre as motivações que levam um indivíduo a praticar crimes.

\footnotetext{
${ }^{1}$ Graduado em Relações Internacionais pela Universidade de Santa Cruz do Sul (UNISC). Pós-graduado em Gestão de Segurança Pública pela UniBF. Policial Penal da SUSEPE/RS.

${ }^{2}$ Graduado em Educação Física pela Universidade da Região da Campanha (URCAMP). Pós-Graduado em Gestão de Segurança Pública pela UniBF. Policial Penal da SUSEPE/RS.

${ }^{3}$ Graduado em Direito pela Faculdade de Direito de Santa Maria (FADISMA). Pós-graduado em Gestão Penitenciária pela Faveni. Pós-graduado em Gestão em Segurança Pública pela Intervale. Pós-graduando em Direito Ambiental pela Intervale. Pós-graduando em Direito Administrativo e Econômico pela Intervale. Pós-graduando em Direito Agrário e A mbiental pela Verbo Jurídico. Policial Penal da SUSEPE/RS.

${ }^{4}$ Graduado em Direito pela Faculdade de Direito de Santa Maria (FADISMA). Pós-Graduado em Inteligência Policial pela Faveni. Policial Penal da SUSEPE/RS.

${ }^{5}$ Graduado em Administração de Empresas pela Universidade da Região da Campanha (URCAMP). Pósgraduado em Segurança Pública pela Faveni. Policial Penal da SUSEPE/RS.

${ }^{6}$ Graduado em Gestão Pública pela Universidade de Franca (UNIFRAN). Pós-graduado em Gestão Pública pela UNIFRAN. Policial Penal da SUSEPE/RS.
} 
Corriqueiramente, são apontadas inúmeras causas para compreender e justificar o que, longe do rigor científico, vem cercadas de várias afirmações baseadas nas experiências e conhecimentos de um determinado grupo social.

Há um número grandioso de variáveis a serem consideradas na análise das atividades criminosas. Portanto, não se pode responsabilizar, isoladamente, um único fator explicativo desta ação, uma vez que vários argumentos poderiam ser testados no intuito de elucidar a problemática "crime".

São várias as correntes que se dispõem a tratar do tema. Contudo, é preciso chamar a atenção para os aspectos que se deseja compreender. Questões sociológicas, regionais e mesmo religiosas são apontadas por muitos como responsáveis pela transformação de indivíduos em agentes que cometam crimes. Todavia, tomar como parâmetro uma variável isolada é insuficiente para julgar o ato criminoso

A Criminologia pode orientar cientificamente através do estudo de observação comportamental de determinados grupos sócios, e pode contribuir para a Política Criminal e para a prevenção e controle do crime e do fenômeno criminal, correspondendo de fato, uma das aspirações do conhecimento científico que é superar o senso comum.

O estudo do crime e do criminoso não são uma exclusão, mas, sim, um terreno de combate, de maneira que fatores extra científicos, tais como a desigualdade na distribuição de poderes, acabam por desempenhar um papel que pode chegar a ser realmente significativos.

Naturalmente, tal função prática de uma ciência, no caso em tela, é buscar entender o que leva o criminoso a cometer crimes de viés econômico, deverá buscar interdisciplinarmente ocupar um espaço nas Ciências Sociais e Humanas, em geral.

O tema desta pesquisa é bastante expressivo para a sociedade, uma vez que trata de uma problemática que ainda necessita de uma maior compreensão de tal fenômeno e ainda possui dificuldades no controle e combate.

Por conseguinte, à futura pesquisa terá por método de abordagem a dedução, já que partirá de casos gerais e genéricos no estudo do crime e do criminoso, haja vista que fatores como desigualdade na distribuição de renda e poderes, acabam por desencadear tal fenômeno.

Partindo de estudos e questões preexistentes já abordadas, o método científico no estudo do fenómeno criminal, e o procedimento a ser realizado será o histórico, conjunto à 
análise comportamental de determinados grupos, visando uma melhor compreensão da temática do estudo da Criminologia e o fenómeno criminal através da teoria do crime, fazendo o uso de pesquisas bibliográficas e documentais.

\section{EVOLUÇÃO DA PENA E A PRIVAÇÃO DA LIBERDADE}

Nos primórdios a humanidade incialmente vivia dividida em pequenos grupos, normalmente unidos por laços familiares, os quais lutavam e com as próprias vidas defendiam seus entes afetivos. Naturalmente e gradativamente foi ocorrendo a evolução humana e estes grupos foram se integrando, assim surgindo as sociedades, ou civilização. Com esse avanço social, também veio a necessidade de se criarem regras de convivência, alternativamente para que se possibilitasse a boa relação entre os indivíduos, e se resguardasse o desenvolvimento da espécie.

Essa alternativa hoje chamada de pena, primeiramente era aplicada na forma bruta, alinhada aos costumes da época. Aqueles que infringiam as regras de convívio, comumente eram penalizados com castigos cruéis no próprio corpo, inclusive grande parte chegando a pena de morte. Os horríveis suplícios perduraram no tempo, e verdadeiros "shows" se apresentavam em pontos e praças públicas para que todos tomassem como exemplo a aplicação da pena, e não cometessem o mesmo ato dos condenados. Nesta linha já expôs BECCARIA (2003, p. 15) escrevendo que "no início as pessoas tinham uma vida selvagem e assim houve a necessidade de se fortalecerem, surgindo desta forma os primeiros bandos e constantemente foram se organizando, constituindo as sociedades, com seus regramentos e leis.”. Disse ainda, que:

O fim, pois, não é outro que impedir o réu de causar novos danos a seus cidadãos e afastar os demais do cometimento de outros iguais. Consequentemente, devem ser escolhidas aquelas penas e aquele método de impô-las, que, respeitada a proporção, causem uma impressão mais eficaz e mais durável sobre o ânimo dos homens e que seja a menos dolorosa para o corpo do réu. (BECCARIA, 1996, p. 46).

Prisões ou celas não existiam no início, mas sim locais onde os intitulados infratores apenas aguardavam o dia em que receberia a retribuição pela que haviam praticado de errado contra seus pares. Muitas distorções nesses bárbaros julgamentos aconteceram, pois no tempo do império e dos reis, o domínio do corpo e da propriedade estava elencado à apenas uma pessoa, o soberano, este o qual se apresentava como vítima, acusador e executor da sentença. 
Já, conforme BARBOSA (1996, p. 2I), “a pena por sua vez, sempre decorreu da vingança privada, exemplificando com a entrega do criminoso à família da vítima, para que desse a ele o destino que quisesse.".

Num segundo momento de evolução foram surgindo novos conceitos de penalização e formas de condenação. Ocorre o surgimento das prisões e a penas vem a ter um caráter mais humano e alternativo aos castigos do corpo. Com isso, o que se pretendia eram atender a novas necessidades da sociedade, ou buscar proteção as pessoas, atendendo melhor seus anseios sociais.

Sobre isso explica NUCCI (2010, p. 57I) que: “a prisão em si, é a privação da liberdade, tolhendo-se o direito de ir e vir, através do recolhimento da pessoa humana ao cárcere.”.

Nessa linha é que surge a privação da liberdade ou encarceramento, para que além de punir o infrator isolando-o dos demais cidadãos, o estado aproveitasse a oportunidade para a reeducação destes. Porém, observa-se ainda hoje, que tais propósitos estão muito longe de serem confirmados, ao passo que o tutor dos condenados, o Governo, se mantém inerte às mazelas do sistema prisional, mantendo-o em abandono estrutural, sem investimentos, agravando ainda mais o caos deste importante instituto social.

O sistema prisional brasileiro não diferente do restante de muitos países subdesenvolvidos, desde o início tem dificuldades enormes de resolver os problemas da prisão e da prisionização. O ente governamental é o principal responsável com o dever de garantir um justo cumprimento da pena, mas infelizmente isto está longe de ser alcançado.

\section{A EVOLUÇÃO DA TEORIA ECONÔMICA DO CRIME E SUAS ORIGENS}

O tráfico de drogas no Brasil representa uma clara consequência dos efeitos da Teoria Econômica do Crime, essencialmente no que tange aos aspectos da incapacidade do estado em aplicar suas normas em determinadas circunstâncias onde o poder do tráfico mantém uma liderança comunitária além do poder estatal.

O viés econômico em relação à escolha do indivíduo em cometer ou não o delito bem como os fatores que sopesam em tal escolha surge com Gary Becker (1968), quando em I968 escreve o artigo "Crime and punischment: an economic approach".

A origem da reflexão que levou Becker (1968) a dissertar sobre o assunto nasce quando em determinada ocasião cotidiana, o autor se depara com uma oportunidade de 
escolha entre arriscar cometer uma infração e aceitar as possíveis penas impostas ou talvez atrasar-se para compromisso importante.

Becker dirigia-se para a Universidade de Columbia, onde aplicaria uma avaliação oral para um aluno. Estando atrasado, Becker deparou-se com a seguinte tomada de decisão: estacionar em um estacionamento particular ou estacionar irregularmente na rua e ser possível alvo de fiscalização e consequente penalização com multa. $\mathrm{Na}$ tomada de decisão, fez um breve calculo mental sobre a probabilidade de ser multado, o peso da multa e o preço de estacionar em estacionamento particular, e decidiu arriscar estacionar seu veículo em local irregular, o que não the rendeu multa alguma [CARDOSO, 2018].

Não é novidade que na sociedade contemporânea não raras vezes depara-se, sobretudo em circunstâncias de trânsito, com inúmeras infrações que "valem a pena", como por exemplo: abandonar o carro em qualquer local irregular em via pública, arriscar a punição com multa e aceitando-a ou atrasar-se para uma reunião inadiável de importância econômica incomparável à consequência de uma multa de trânsito.

Obviamente, o aspecto econômico supera a consequência administrativa ora em discussão, todavia, no que toca às consequências criminais como as do cometimento do tráfico de drogas, não se tem a mesma percepção óbvia de escolha econômica, conforme abordagem posterior.

Em que pese a Teoria Econômica do Crime ter seu corpo formado na análise econômica realizada por Gary Becker, o embrião de tais reflexões econômicas acerca do delito tem origem nas premissas de Cesare Beccaria e Jeremy Bentham que aliaram ao estudo do crime ao cálculo econômico do delito na sua essência [CARDOSO, 2018].

Pode-se afirmar, portanto, que a Teoria Econômica do Crime configura-se como uma espécie de ressurgimento moderno desses estudos pioneiramente elaborados pelos doutrinadores supracitados.

Por mais que os ensinamentos de Bentham e Beccaria não contem com a sofisticação técnica que configura a Teoria Econômica do Crime, alguns fatores econômicos relevantes estão presentes nas suas respectivas doutrinas, senão vejamos.

$\mathrm{Na}$ obra Dos delitos e das penas [BECCARIA, 200o], desde sua publicação original em i764, Beccaria muda a forma como se enfrentam as realidades do crime a das penas, bem como uma substancial parcela de inovação da teoria em exame deve ser creditada aos estudos provenientes de Cesare Beccaria.

Sobrepõe-se, todavia, que Beccaria tinha por pressuposto de que, por mais delituoso que seja o indivíduo, a ele deverá sobressaltar a ideia de que o comportamento humano está 
obrigatoriamente atrelado ao desejo de aumentar seu bem estar e diminuir o sofrimento [MENDES, 2007].

Da mesma forma, Bentham desenvolveu em sua obra um entendimento predominantemente econômico a respeito dos crimes e das penas. É clarividente que Bentham sofre substancial influência de Cesare Beccaria e, em razão disso, creditou diversos trabalhos.

Os fatores econômicos contidos na obra de Beccaria e Bentham dizem respeito, primordialmente, ao fator racional dos agentes: considerava-se, dessa forma, que os humanos são seres racionais e que, portanto, são atraídos pelo delito somente se o custobenefício for favorável, ou seja, se os lucros preponderarem em valor em detrimento de uma possível pena.

Cesare Beccaria e Jeremy Bentham enfatizam, ainda, a importância da certeza e da correlação próxima da pena; dessas forma, mais do que rígida a aplicação da punição deveria ser certeira e célere.

Cumpre ressaltar que, assim como Beccaria e Bentham, Montesquieu contribuiu também com a evolução da Teoria Econômica do Crime ao sustentar que as ações dos indivíduos sofrem influência de diversos fatores, quais sejam, por exemplo: a educação recebida na infância, a religião, a geografia, suas crenças, ocorrências passadas e também a forma de governo a qual se submete. Entrementes, é penoso afirmar que o indivíduo que age solitariamente está observando circunstâncias de fatores externos que não sejam somente os fatores inerentes aos da vontade do agente [ALBUQUERQUE, Ca. 2006].

Necessário também ressaltar que a ideia basilar do modelo adotado por Becker tem como suporte a ponderação adotado pelo indivíduo entre custos de determinada prática criminosa e benefícios ou expectativas de benefícios com a prática do crime. Para tanto, Daniel Cerqueira e Waldir Lobão comprimem o entendimento de Becker na seguinte expressão acerca da Teoria da Escolha Racional:

Gary Becker (1968), com o artigo seminal "Crime and Punishment: An Economic Approach", impôs um marco à abordagem sobre os determinantes da criminalidade ao desenvolver um modelo formal em que o ato criminoso decorreria de uma avaliação racional em torno dos benefícios e custos esperados aí envolvidos, comparados aos resultados da alocação do seu tempo no mercado de trabalho legal Basicamente, a decisão de cometer ou não o crime resultaria de um processo de maximização de utilidade esperada, em que o indivíduo confrontaria, de um lado, os potenciais ganhos resultantes da ação criminosa, o valor da punição e as probabilidades de detenção e aprisionamento associadas e, de outro, o 
custo de oportunidade de cometer crime, traduzido pelo salário alternativo no mercado de trabalho [CERQUEIRA; LOBÃO, 2004, p. 247].

O modelo definido por Becker, por outro lado, também busca formular um cálculo de prejuízo social resultante de conduta criminosa no encontro de recursos utilizados pelo poder público para reduzir tais perdas, conduzindo o estudo para uma melhor alocação de recursos em políticas públicas de segurança e prevenção com a consequência de haver maior efetividade na aplicação de sanções bem como redução de danos decorrentes do cometimento de delitos [PIRES, 2015].

\section{CONSIDERAÇÕES FINAIS}

O intuito do presente desenvolvimento científico foi o de apresentas os diversos pontos de vista e diferentes correntes acerca da Teoria Econômica do Crime bem como as nuances que envolvem a temática inerente ao crime, propriamente dito.

Dessa forma, como a linha de exposição foi a de evidenciar delitos cometidos contra o patrimônio, constatou-se que o crescimento econômico é um vetor substancial na majoração de crimes dessa espécie, uma vez que aumentam-se os retornos esperados.

Todavia, não significa que as linhas doutrinárias que apresentem outras variáveis justificantes do cometimento de crimes desta espécie não sejam verdadeiras. Infere-se, dessa forma, que outras linhas apenas não são suficientes para justificar a opção do indivíduo pela atividade criminosa, vez que a racionalidade "benefícios" do delito deve ser levada em consideração na tomada de decisão do indivíduo criminoso.

\section{REFERÊNCIAS BIBLIOGRÁFICAS}

ALBUQUERQUE, J. A. Guilhon. Montesquieu: sociedade e poder. Ca. 2006.

Disponível em: http://www.ceap.br/artigos/ARTi310201195007.pdf. Acesso em: i4. out. 2021.

ANDRADE, E. L. Introdução à Pesquisa Operacional: Métodos e Modelos para Análise de Decisão. $2^{\underline{a}}$ ed., LTC, Rio de Janeiro, 2000

ARAÚJO, Jorge Luiz Medeiros e CARVALHO, Alcione da Costa. Violência, educação e exclusão social na região norte de Natal. Disponível em: http://webserver.falnatal.com.br/revista_nova/a6_v3/Artigo_violencia_ZN_\%2oDireito.p df. Acesso em 22. set. 2021 
BARBOSA, Marcelo Fortes. Direito Penal Atual: Estudos. São Paulo: Malheiros Editores LTDA, 1996.

BECCARIA, Cesare. Dos delitos e das penas. 2. ed. Trad. Torrieri Guimarães. São Paulo: Martin Claret, 2000.

BECKER, Gary; LANDES, William M. Crime and punischment: an economic approach. Disponível <https://www.journals.uchicago.edu/doi/pdfplus/ı.1086/259394〉em: Acesso em II. out. 2021.

BRITTO, Tatiana A. Desemprego e crime: uma análise de séries de tempo para o Distrito Federal: 1992 a 1996. Brasília: Dissertação (Mestrado), 46 p. Departamento de Economia universidade de Brasília, 1999.

CARDOSO, Luiz Eduardo Dias. A Teoria Econômica do Crime: uma breve introdução. Disponível em: <https://consultorpenal.com.br/a-teoria-economica-do-crime-uma-breveintroducao $>$. Acesso em II. out. 202I.

CERQUEIRA, Daniel; LOBÃO, Waldir. Determinantes da criminalidade: arcabouços teóricos e resultados empíricos - 2004. Disponível em: 〈http://www.scielo.br/pdf/dados/v47n2/ao2v47n2.pdf〉. Acesso em 12. out. 2021.

HASSON. M. E; MELEIRO. A. M. A. S. Reflexões sobre a desestruturação familiar e a criminalidade. In: RIGONATTI, S. P. (Coord.). Temas em Psiquiatria Forense e Psicologia Jurídica. São Paulo: Vetor, 2003. p. 79-104.

KAHN, Túlio. Cidades Blindadas - ensaios de criminologia. Conjuntura Criminal, São Paulo, 200I.

MENDES, S. M. Análise Econômica do Crime e o seu Contributo para a Definição de uma Política Penal. 2007. Disponível em: 〈http://repositorium.sdum.uminho.pt/handle/I822/4228〉. Acesso em I4. out. 202I.

NUCCI, Guilherme de Souza. Manual de Processo Penal e Execução Penal. 6 ${ }^{a}$ ed. São Paulo: Revista dos Tribunais Ltda., 2010.

PIRES, Adriane da Fonseca. A Economia do Crime: precisamos falar sobre Gary Backer. 2015. Disponível em: <https://canalcienciascriminais.com.br/a-economia-do-crimeprecisamos-falar-sobre-gary-becker/>. Acesso em: 12. out. 2021.

VIAPIANA, Luiz Tadeu. Economia do crime: uma explicação para a formação do criminoso. Editora AGE Ltda. 2006.

ZALUAR, Alba. Da revolta ao crime. São Paulo: Moderna, 1997. 